\title{
Effectiveness of nifedipine in threatened preterm labor: a randomized trial
}

This article was published in the following Dove Press journal:

International Journal of Women's Health

\author{
Srisuda Songthamwat \\ Chatchanawadee $\mathrm{Na} \mathrm{Nan}$ \\ Metha Songthamwat \\ Department of Obstetrics and \\ Gynecology, Udonthani Hospital, \\ Udonthani, Thailand
}

\begin{abstract}
Objective: Threatened preterm labor is a condition in which regular uterine contractions occur at least 1 time in 10 minutes and persist for more than 30 minutes before completion of 37 weeks of gestation without dilatation of the cervix. In preterm labor with cervical dilatation, the efficacy of tocolytics was proven for prolonging pregnancy. However, in threatened preterm labor, the efficacy of tocolytics has not yet been well studied. This study aimed to evaluate the effectiveness of nifedipine versus a placebo for inhibiting uterine contraction in threatened preterm labor.
\end{abstract}

Materials and methods: A randomized, double-blinded, placebo-controlled study with 206 threatened preterm labor patients was undertaken. The participants were randomly allocated into either nifedipine or placebo groups. The proportion of patients with successful treatment, gestational age at delivery, and neonatal outcome were compared between the 2 groups.

Results: After 90 minutes of treatment, $88.3 \%$ of the nifedipine group and $69.9 \%$ of the placebo group had no uterine contraction $(P<0.001)$. Nifedipine led to successful treatment outcomes in $77.6 \%$ of the total participants compared with $49.5 \%$ in the placebo group $(P<0.001)$. The remainder of the participants from both groups needed a second-line tocolytic drug. Of these, $9.7 \%$ in the nifedipine group delivered within 48 hours compared with $12.6 \%$ in the placebo group $(P>0.05)$. Mean gestation age at delivery and neonatal complications for both groups were not significantly different.

Conclusion: Nifedipine had a higher success rate for inhibiting threatened preterm contractions.

Keywords: nifedipine, threatened preterm labor, preterm labor, tocolysis, randomized trial

\section{Introduction}

All pregnant women are taught about the symptoms of premature labor by the antenatal care practice. Should uterine contractions occur, they are to be self-monitored, and if regular painful contractions are detected the women have to go to the hospital for examination. Upon examination, many women who had regular contractions without cervical dilatation did not meet the criteria for preterm labor. This condition was reported as "threatened preterm labor," which is defined as "the condition in which regular uterine contraction of at least 1 time in 10 minutes persisting for more than 30 minutes before 37 weeks of gestation without dilatation of the cervix." "Where threatened preterm labor was reported, it may proceed to an advanced stage of labor and delivery in about $30 \%$ of cases. $^{2}$

Every year, an estimated 15 million babies are born prematurely, and this number is increasing. Preterm birth complications are the leading cause of death among children under 5 years of age, and it was responsible for nearly 1 million deaths in 2015. ${ }^{3}$ Three-quarters of these deaths were preventable with current, cost-effective interventions. ${ }^{4}$ Across 184 countries, the preterm birth rate ranges from $5 \%$ to $18 \%$

\footnotetext{
Correspondence: Metha Songthamwat Department of Obstetrics and Gynecology, Udonthani Hospital, 33 Por-niyom Road, Muang, Udonthani 41000, Thailand

Tel +6642245555

Fax +66 422477 II

Email udonhome@yahoo.com
}

International Journal of Women's Health 2018:10 317-323

(c) (i) () 2018 Songthamwat et al. This work is published and licensed by Dove Medical Press Limited. The full terms of this license are available at https://www.dovepress.com/terms.php cc) and incorporate the Creative Commons Attribution - Non Commercial (unported, v3.0) License (http://(creativecommons.org/licenses/by-nc/3.0/). By accessing the work you hereby accept the Terms. Non-commercial uses of the work are permitted without any further permission from Dove Medical Press Limited, provided the work is properly attributed. For permission for commercial use of this work, please see paragraphs 4.2 and 5 of our Terms (https://www.dovepress.com/terms.php). 
of live births. ${ }^{5,6}$ This accounts for $\sim 70 \%$ of neonatal deaths and $36 \%$ of infant deaths, as well as $25 \%-50 \%$ of the cases having long-term neurological impairment. ${ }^{7}$

In preterm labor with cervical dilatation, the efficacy of tocolytic drugs has been proven to prolong pregnancy. ${ }^{8} \mathrm{~A}$ commonly used tocolytic drug is nifedipine which appears to be more effective than $\beta_{2}$-adrenergic-receptor agonists and magnesium sulfate. ${ }^{9,10}$ Other treatments such as progesterone and bed rest were also studied. ${ }^{1}$ Nifedipine is considered as the first-line tocolytic agent for the management of preterm labor. ${ }^{10,11}$ However, in threatened preterm labor the efficacy of nifedipine has not yet been well studied. It is for this reason that we conducted a randomized, double-blinded, placebo-controlled study to assess nifedipine's efficacy in threatened preterm labor.

\section{Materials and methods}

This study was a randomized, double-blinded, placebocontrolled study and was conducted from December 1, 2016 to July 31, 2017 at Udonthani Hospital, Thailand. The proposal of this study was approved by the Ethical Research Committee of Udonthani Hospital No 21/2559 and was registered in the Clinical Trial Registry No TCTR20161104004. The inclusion criteria were singleton pregnant women, aged between 18 and 35 years who were admitted to the labor room for threatened preterm labor.

Threatened preterm labor was diagnosed as a condition where the pregnancy was between 24 and 36 weeks of gestation with painful and regular uterine contractions at least 1 time every 10 minutes and persisting for more than 30 minutes without dilatation of the cervix. ${ }^{1}$ Uterine contraction was recorded by external electronic fetal heart rate monitoring for 30 minutes. In all cases, gestational age was calculated from last menstrual period, with the result confirmed by an ultrasonography in the first half of the pregnancy.

Exclusion criteria were cervical dilatation $\geq 2 \mathrm{~cm}$, cervical incompetence, ruptured membranes, contraindications for inhibition of labor, nifedipine allergy, and unwillingness to participate in this study.

The explanation of the research program and obtaining of the written informed consent were done at the labor room. Then, all participants were randomly allocated into 1 of 2 study groups by block randomization, using a computer-generated number and sealed opaque envelopes, was performed. The drug and the placebo were prepared in similar packages and numbered by the researchers. The drug in the package was given to the participants by the nurses.
The first group $(\mathrm{N}=103)$ received the first loading dose of nifedipine $20 \mathrm{mg}$ orally, and then continuous electronic fetal monitoring was done to evaluate uterine contractions. If uterine contractions persisted, then $20 \mathrm{mg}$ of nifedipine was given every 30 minutes with a maximum total of 3 doses. After regular uterine contractions stopped, a maintenance dose using nifedipine $20 \mathrm{mg}$ was given orally every 8 hours, ${ }^{10,12}$ and the placebo group $(\mathrm{N}=103)$ received a placebo orally with the same schedule as the nifedipine group.

The uterine contractions were monitored by continuous electrical external fetal monitoring in the first 90 minutes after nifedipine and placebo were administered, then every 6 for 24 hours. ${ }^{10,12}$ The uterine contraction and fetal heart sounds were also observed manually as per the standard protocol of preterm labor treatment. Maternal blood pressure was recorded every 15 minutes in the first 2 hours after the loading dose, and then as usual. The side effects of nifedipine, such as transient hypotension, tachycardia, flushing, headache, dizziness, and nausea, were observed for and treated during the intervention. ${ }^{10,12,13}$ Both nifedipine and the placebo were continued for 48 hours.

Successful treatment was defined as a pregnancy which was prolonged for more than 48 hours by nifedipine or the placebo without indication for changing to a second-line tocolytic drug. Unsuccessful treatment was the persistence of regular uterine contractions and the need to change to a second-line tocolytic drug or delivery within 48 hours of treatment.

The second-line drug was terbutaline. It was used in those cases of unsuccessful treatment and in cases where there was no contraindication for terbutaline, by intravenous drip, adjusted for inhibition of uterine contraction. ${ }^{14}$ Then, 4 doses of $6 \mathrm{mg}$ dexamethasone were given intramuscularly every 12 hours for promotion of fetal lung maturity. ${ }^{15,16}$

The participants were followed until delivery. The proportion of participants with successful treatment, maternal complications, gestational age at delivery, proportion of delivery within 48 hours after treatment, proportion of delivery before 37 weeks gestation, and neonatal outcome were compared between the 2 groups.

The sample size calculation was based on the previous study (Chawanpaiboon et $\mathrm{al}^{1}$ ), and the proportion of successful outcomes in the control group was 0.6 and in the treatment group was 0.8 . $\alpha$ was 0.05 , and the power was $80 \%$. The calculated sample size was 98 participants in each group. A total number of 206 participants with 103 per group were included. The groups were compared using an unpaired Student's $t$-test for continuous variables and $\chi^{2}$ and 
Fisher exact tests for categorical variables. The relative risk with a 95\% confidence interval (CI) was calculated for the magnitude of effect. Statistical analysis was performed using Stata version13 (Stata Corp, College Station, TX, USA). $P$-value $<0.05$ was considered statistically significant.

\section{Results}

The study included 206 participants who were randomly allocated into 1 of 2 groups. The nifedipine group and the placebo group each had 103 participants. The Consort diagram is presented in Figure 1. The participants' characteristics in both groups are shown in Table 1. Both groups were comparable in terms of maternal age, parity, and number of previous preterm births, except for gravidity and number of previous abortions. The mean gestational age at the beginning of study was 33.6 weeks (range 25-36 weeks). Of the participants, $32.6 \%$ were nulliparous and $10.2 \%$ had history of previous preterm birth.

At 90 minutes after treatment, the nifedipine group had no uterine contraction in 91 cases $(88.3 \%)$ after 3 loading doses compared with 72 cases (69.9\%) in the placebo group which had spontaneous resolution of their contraction (adjusted relative risk $=1.27,95 \% \mathrm{CI}=1.10-1.47$, number needed to treat $[\mathrm{NNT}]=5.6$ ).

The unsuccessful cases in both groups (those who still had uterine contraction at 90 minutes after starting treatment) received terbutaline intravenous drip for inhibiting uterine contraction. The successful treatment cases in both groups (no regular uterine contraction) were observed clinical of painful regular contraction and external electronic fetal heart rate monitoring was done every 6 hours. If regular uterine contractions were seen, more than 1 time every 10 minutes persisting for more than 30 minutes, terbutaline was given to inhibit contraction.

At 48 hours after treatment began, successful treatment was found in 80 cases $(77.6 \%)$ in the Nifedipine group compared with 51 cases $(49.5 \%)$ in the placebo group (adjusted relative risk $=1.52,95 \% \mathrm{CI}=1.22-1.91$, NNT =3.6) (Table 2).

The data also showed that 10 cases $(9.7 \%)$ in the nifidipine group and 13 cases (12.6\%) in the placebo group were not successful in inhibiting labor, even after changing to terbutaline treatment, and delivered within 48 hours after admission (adjusted relative risk $=1.05,95 \% \mathrm{CI}=0.95-1.12$, NNT $=34.3$ ) (Figure 2).

The complications of nifedipine observed were transient hypotension in 4 cases $(3.8 \%)$ and transient tachycardia in 2 cases $(1.9 \%)$. The complications were successfully treated by intravenous fluid and observation. No serious cardiovascular or fetal complications were found in both groups.

After successful treatment, the participants were discharged from the hospital after 24 hours and were followed at the high-risk antenatal care clinic. It was found that $76.7 \%$ of

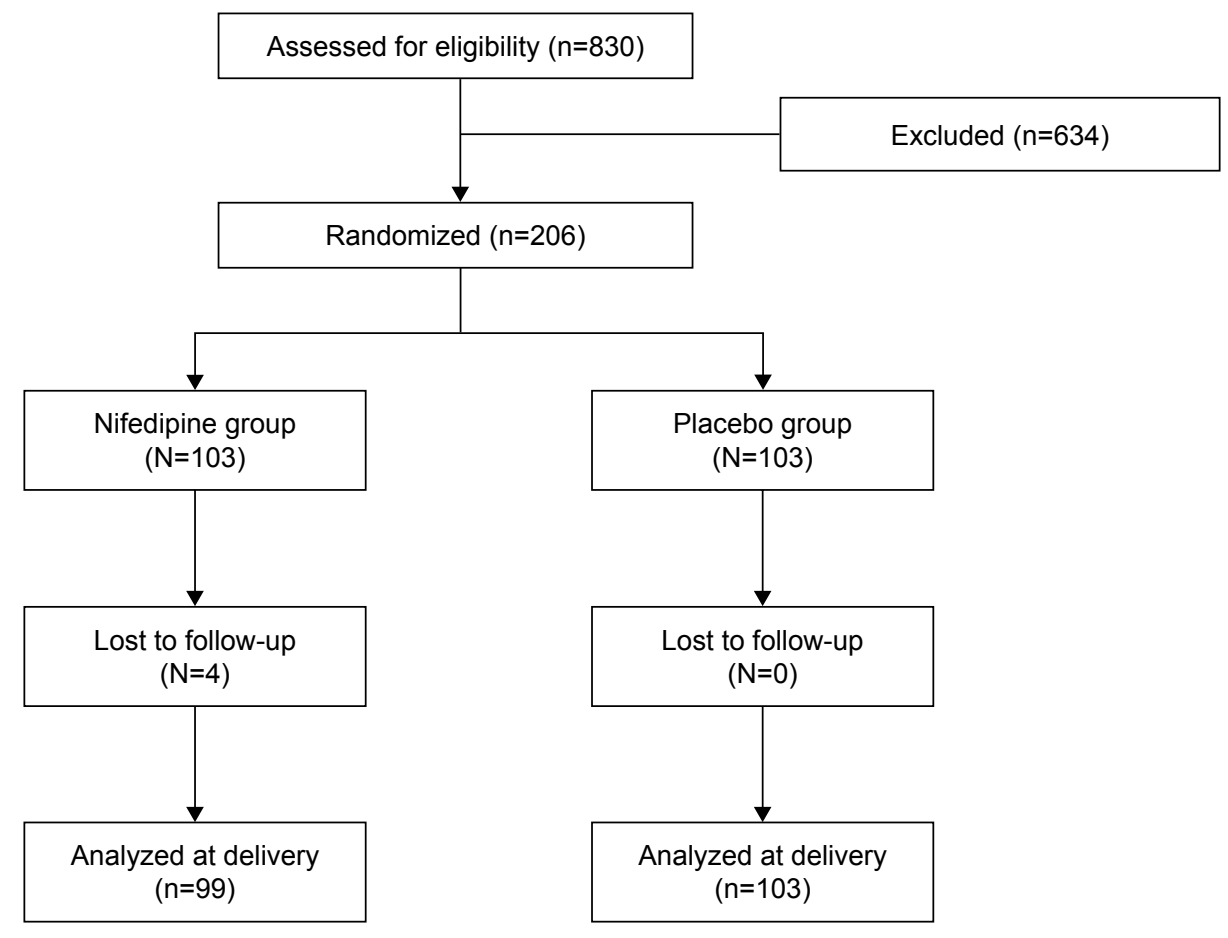

Figure I Consort diagram. 
Table I Comparison of epidemiological characteristics

\begin{tabular}{|c|c|c|}
\hline Data & $\begin{array}{l}\text { Nifedipine } \\
\text { group } \\
(\mathbf{N}=\mid 03)\end{array}$ & $\begin{array}{l}\text { Placebo } \\
\text { group } \\
(\mathrm{N}=103)\end{array}$ \\
\hline Maternal age (years; mean) & 27.1 (SD 5.73) & $25.6(\mathrm{SD} 5.85)$ \\
\hline Gravid (mean) & $2.28(\mathrm{SD}$ I.I7) & I.87 (SD 0.89) \\
\hline Parity (mean) & 0.89 (SD 0.76) & 0.70 (SD 0.79) \\
\hline Previous abortion, n (\%) & $28(27.1 \%)$ & 15 (I4.5\%) \\
\hline Previous cesarean section, $\mathrm{n}(\%)$ & $27(25.9 \%)$ & $17(16.5 \%)$ \\
\hline History of preterm birth, n (\%) & $13(12.5 \%)$ & $8(7.7 \%)$ \\
\hline Smoking, n (\%) & $4(1.94 \%)$ & $2(3.85 \%)$ \\
\hline Infection, $\mathrm{n}(\%)$ & $15(14.0 \%)$ & $17(16.5 \%)$ \\
\hline Mean gestational age (weeks) & 33.6 (SD 2.48) & 33.4 (SD 2.52) \\
\hline Body weight (kg) & 67.1 (SD |4.25) & $64.0(\mathrm{SD} 10.19)$ \\
\hline Body mass index $\left(\mathrm{kg} / \mathrm{m}^{2}\right)$ & $26.9(\mathrm{SD} 0.53)$ & $26.2(\mathrm{SD} 0.39)$ \\
\hline Initial dilatation of cervix $(\mathrm{cm})$ & $0.20(\mathrm{SD} 0.40)$ & 0.17 (SD 0.37) \\
\hline
\end{tabular}

Abbreviation: SD, standard deviation.

the nifidipine group and $74.8 \%$ of the placebo group delivered at more than 37 weeks gestational age (adjusted relative risk $=1.01,95 \% \mathrm{CI}=0.91-1.12, P=0.86, \mathrm{NNT}=98.8)$.

The mean gestational age at delivery and mode of delivery were not significantly different in both groups. The mean neonatal birth weight and neonatal outcome between both groups were also not statistically significantly different (Table 3).

\section{Discussion}

Preterm birth remains an unsolved problem in obstetrics and neonatology. The etiology of prematurity is still questionable, and treatment is still problematic in clinical practice. ${ }^{17,18}$ Many interventions have been studied for the prevention and treatment of preterm labor. Nevertheless, one of the most common methods is the use of tocolytic drugs for inhibiting uterine contraction. ${ }^{7,10}$

Threatened preterm labor, which is regular uterine contraction without cervical progression, is problematic in its management. Threatened preterm labor can progress to preterm labor and preterm birth. From this study, about $10 \%$ of threatened preterm labor progressed to delivery after treatment, which was less than that reported in a previous study. ${ }^{2}$ This showed the importance of threatened preterm labor treatment. Close observation and a prepared preterm neonatal care team are also necessary for inhibiting threatened preterm labor.

Nifedipine is a calcium channel blocker which has been commonly used in the treatment of preterm labor with dilation of the cervix, with good results. ${ }^{11}$ However, the main benefit of a tocolytic drug is the prolongation of pregnancy for a 48-hour period to allow the steroid effect to enhance fetal lung maturity. ${ }^{15,16}$ From this study, it can be seen that nifidipine can inhibit the uterine contraction in about $77.6 \%$ of threatened preterm labor cases, which was comparable with the results of a previous study. ${ }^{1}$ The efficacy of nifedipine in threatened preterm labor was also proven, as in preterm labor with cervical dilatation. ${ }^{11}$

The complications of nifedipine were transient hypotension in 4 cases $(3.8 \%)$ and transient tachycardia in 2 cases $(1.9 \%)$. This was less than the previous study which reported the cardiovascular complication of nifedipine in $17.3 \%$ of cases. ${ }^{19}$ For this reason, close observation of maternal vital signs is recommended during the nifedipine treatment.

The mean gestation age of delivery in both groups after treatment was 37 weeks. This study showed that 13 cases (6.9\%) after being discharged from the hospital had to be readmitted for preterm labor. This rate was similar to the rate in studies of preterm labor with cervical dilatation. ${ }^{20,21}$ The rates of term delivery, birth weight, and neonatal complications between the nifedipine and the placebo groups were not significantly different. These rates were similar to the rates in studies of preterm labor with cervical dilatation. ${ }^{9,22}$

The strength of this study is the prospective randomized, double-blinded, placebo-controlled study design. The block randomization using opaque envelopes was a good representation of the population. However, the limitation of this study is the sample size, which was calculated from the proportion of successful treatment in both groups in 48 hours, and therefore the difference between neonatal complication and delivery rate at term in both groups needs further study with a larger sample size to evaluate this difference.

Table 2 Numbers of successful patients with regard to inhibition and delivery data in nifedipine and placebo groups

\begin{tabular}{|c|c|c|c|c|c|c|}
\hline Outcome & Nifedipine & Placebo & $\mathbf{R} \mathbf{R}$ & Adjusted $\mathbf{R R}^{\mathbf{a}}$ & $95 \% \mathrm{Cl}$ & NNT \\
\hline Successful at 90 minutes, $n$ (\%) & $91 / 103$ (88.3\%) & $72 / 103$ (69.9\%) & 1.18 & 1.27 & $1.10-1.47^{\mathrm{b}}$ & 5.6 \\
\hline Successful after 48 hours, n (\%) & $80 / 103(77.6 \%)$ & $5 \mathrm{I} / \mathrm{I} 03(49.5 \%)$ & 1.57 & 1.52 & $1.22-1.91^{\mathrm{b}}$ & 3.6 \\
\hline Delayed delivery $\geq 48$ hours, $n(\%)$ & $93 / 103$ (90.3\%) & $90 / 103$ (87.4\%) & 1.03 & 1.05 & $0.95-1.15$ & 34.3 \\
\hline Delivery $\geq 37$ weeks, n (\%) & 73/99 (76.7\%) & 77/I03 (74.8\%) & 0.99 & 1.01 & $0.91-1.12$ & 98.8 \\
\hline
\end{tabular}

Notes: ${ }^{a}$ Adjusted for gravid and previous abortion. 'Statistically significant.

Abbreviations: $\mathrm{Cl}$, confidence interval; RR, relative risk; NNT, number needed to treat. 


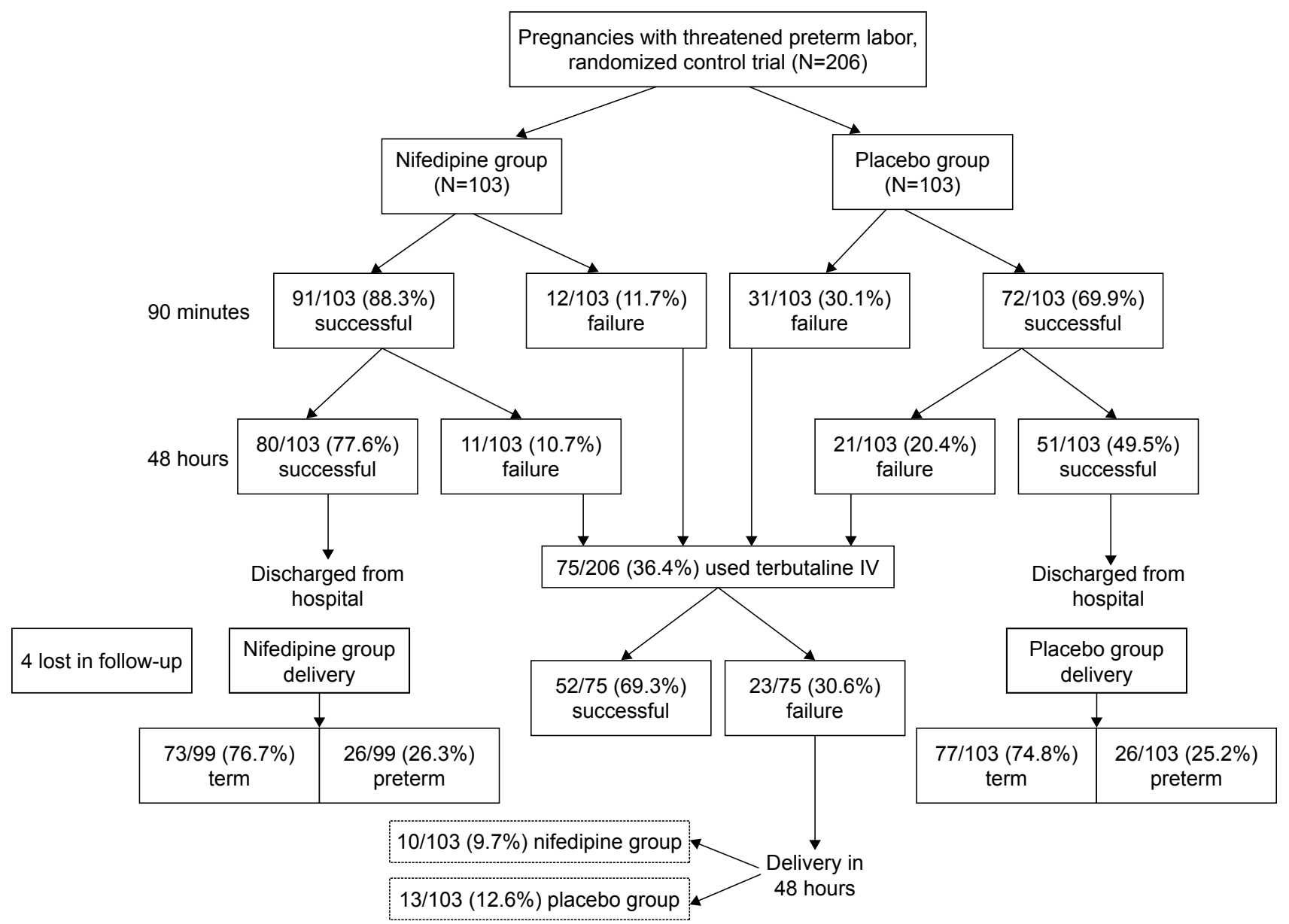

Figure 2 Flow diagram of the pregnancies with threatened preterm labor between nifedipine and placebo groups.

Table 3 Delivery and newborn data

\begin{tabular}{|c|c|c|c|}
\hline Outcome & Nifedipine (N=99) & Placebo $(\mathrm{N}=103)$ & $P$-value \\
\hline Gestational age at delivery (weeks) (mean) & 37.26 (SD I.56) & 37.17 (SD I.84) & $0.7 \mathrm{I}$ \\
\hline Duration for delaying delivery (weeks) (mean) & 3.56 (SD 2.70) & 3.71 (SD 2.88) & 0.70 \\
\hline \multicolumn{4}{|l|}{ Mode of delivery } \\
\hline Vaginal delivery, n (\%) & $46(46.5 \%)$ & 72 (69.9\%) & - \\
\hline Cesarean section, n (\%) & $53(53.5 \%)$ & $31(30.1 \%)$ & - \\
\hline \multicolumn{4}{|l|}{ Maternal complication at delivery, $\mathrm{n}(\%)$} \\
\hline Preeclampsia & $2(2.02 \%)$ & $2(1.94 \%)$ & - \\
\hline Chorioamnionitis & 0 & $2(1.94 \%)$ & - \\
\hline Postpartum hemorrhage & $3(3.03 \%)$ & $3(2.91 \%)$ & - \\
\hline Fetal distress & $8(8.08 \%)$ & $5(4.85 \%)$ & - \\
\hline Cephalopelvic disproportion & $6(6.06 \%)$ & I (0.97\%) & - \\
\hline Neonatal birth weight (g) (mean) & 2,999.3 (SD 54I.5) & 2,920.9 (SD 394.2) & 0.24 \\
\hline \multicolumn{4}{|l|}{ APGAR score } \\
\hline I minute & 8.76 (SD I.2I) & 9.06 (SD 0.82) & $0.04^{a}$ \\
\hline 5 minutes & 9.80 (SD I.48) & 9.91 (SD 0.3I) & 0.45 \\
\hline \multicolumn{4}{|l|}{ Neonatal complication, n (\%) } \\
\hline Respiratory distress syndrome & $10(10.10 \%)$ & 7 (6.80\%) & - \\
\hline Jaundice & I (I.0I\%) & 0 & - \\
\hline Sepsis & I (I.0I\%) & I (0.97\%) & - \\
\hline Death & $\mathrm{I}(\mathrm{I} .0 \mathrm{I} \%)$ & 0 & - \\
\hline
\end{tabular}

Note: aStatistically significant.

Abbreviation: SD, standard deviation. 
The clinical implication of this research is our recommendation of using nifedipine for inhibiting uterine contraction in threatened preterm labor. However, within the first 90 minutes of treatment, $69.9 \%$ of the participants with threatened preterm labor in the placebo group had self-spontaneous resolution of their contraction. For this reason, we recommend bed rest and close observation for 60-90 minutes before starting tocolytic treatment in threatened preterm labor to avoid unnecessary tocolytic treatment. The type and dosage of tocolytic drugs which is most effective for threatened preterm labor still needs further study.

\section{Conclusion}

Nifedipine treatment did inhibit uterine contraction in threatened preterm labor at a higher rate than the placebo. However, $69.9 \%$ of the cases with threatened preterm contraction did spontaneously resolve within 90 minutes. Therefore, 60-90 minutes of bed rest is suggested before tocolytic drug use for inhibiting threatened preterm labor to avoid the complications from unnecessary tocolysis treatment.

\section{Acknowledgments}

We acknowledge Dr Thammanoon Wisittanawat, Director of Udonthani Hospital, for permission and grant support. We also thank the Udonthani Hospital staff and all participants who participated in this trial. This study was supported by Udonthani Hospital.

\section{Disclosure}

The authors report no conflicts of interest in this work.

\section{References}

1. Chawanpaiboon S, Pimol K, Sirisomboon R. Comparison of success rate of nifedipine, progesterone, and bed rest for inhibiting uterine contraction in threatened preterm labor. J Obstet Gynaecol Res. 2011;37(7): 787-791.

2. Chawanpaiboon S, Sutantawibul A, Pimol K, Sirisomboon R, Worapitaksanond S. Preliminary study: comparison of the efficacy of progesterone and nifedipine in inhibiting threatened preterm labour in Siriraj Hospital. Thai J Obstet Gynaecol. 2009;17(1):23-29.

3. Liu L, Oza S, Hogan D, et al. Global, regional, and national causes of child mortality in 2000-13, with projections to inform post-2015 priorities: an updated systematic analysis. Lancet. 2015;385(9966):430-440.

4. Bhutta ZA, Das JK, Bahl R, et al. Can available interventions end preventable deaths in mothers, newborn babies, and stillbirths, and at what cost? Lancet. 2014;384(9940):347-370.
5. Leonard SA, Crespi CM, Gee DC, Zhu Y, Whaley SE. Prepregnancy risk factors for preterm birth and the role of maternal nativity in a low-income, hispanic population. Matern Child Health J. 2015;19(10):2295-2302.

6. Lawn JE, Kinney MV, Belizan JM, et al. Born too soon: accelerating actions for prevention and care of 15 million newborns born too soon. Reprod Health. 2013;10(Suppl 1):S6.

7. The American College of Obstetricians and Gynecologists. Management of preterm labor. Practice Bulletin no. 159. Obstet Gynecol. 2016;127(1):e29-e38.

8. Haas DM, Imperiale TF, Kirkpatrick PR, Klein RW, Zollinger TW, Golichowski AM. Tocolytic therapy: a meta-analysis and decision analysis. Obstet Gynecol. 2009;113(3):585-594.

9. Haas DM, Caldwell DM, Kirkpatrick P, McIntosh JJ, Welton NJ. Tocolytic therapy for preterm delivery: systematic review and network meta-analysis. BMJ. 2012;345:e6226.

10. Conde-Agudelo A, Romero R, Kusanovic JP. Nifedipine in the management of preterm labor: a systematic review and metaanalysis. $\mathrm{Am}$ J Obstet Gynecol. 2011;204(2):134.e1-e20.

11. Flenady V, Wojcieszek AM, Papatsonis DN, et al. Calcium channel blockers for inhibiting preterm labour and birth. Cochrane Database Syst Rev. 2014;(6):CD002255.

12. The Royal Thai College of the Obstetricians and Gynaecologists. Clinical practice guideline OB014: The Management of Preterm labour and Premature Rupture of Membranes. Thailand: The Royal Thai College of the Obstetricians and Gynaecologists; 2015:15-42.

13. Cornette J, Duvekot J, Roos-Hesselink J, Hop W, Steegers E. Maternal and fetal haemodynamic effects of nifedipine in normotensive pregnant women. BJOG. 2011;118(4):510-515.

14. Neilson JP, West HM, Dowswell T. Betamimetics for inhibiting preterm labour. Cochrane Database Syst Rev. 2014;(2):CD004352.

15. Committee on Obstetric Practice. Committee Opinion No. 713: antenatal corticosteroid therapy for fetal maturation. Obstet Gynecol. 2017; 130(2):e102-e109.

16. Roberts D, Brown J, Medley N, Dalziel SR, Julie B. Antenatal corticosteroids for accelerating fetal lung maturation for women at risk of preterm birth. Cochrane Database Syst Rev. 2017;3:CD004454.

17. The American College of Obstetricians and Gynecologists; Committee on Practice Bulletins - Obstetrics. ACOG practice bulletin no. 127: management of preterm labor. Obstet Gynecol. 2012;119(6):1308.

18. McIntire DD, Leveno KJ. Neonatal mortality and morbidity rates in late preterm births compared with births at term. Obstet Gynecol. 2008; 111(1):35-41.

19. Salim R, Garmi G, Nachum Z, Zafran N, Baram S, Shalev E. Nifedipine compared with atosiban for treating preterm labor: a randomized controlled trial. Obstet Gynecol. 2012;120(6):1323-1331.

20. Hackney DN, Olson-Chen C, Thornburg LL. What do we know about the natural outcomes of preterm labour? A systematic review and meta-analysis of women without tocolysis in preterm labour. Paediatr Perinat Epidemiol. 2013;27(5):452-460.

21. Nassar AH, Abu-Musa AA, Awwad J, Khalil A, Tabbara J, Usta IM. Two dose regimens of nifedipine for management of preterm labor: a randomized controlled trial. Am J Perinatol. 2009;26(8):575-581.

22. Abramovici A, Cantu J, Jenkins SM. Tocolytic therapy for acute preterm labor. Obstet Gynecol Clin North Am. 2012;39(1):77-87. 
International Journal of Women's Health

Dovepress

\section{Publish your work in this journal}

The International Journal of Women's Health is an international, peerreviewed open-access journal publishing original research, reports, editorials, reviews and commentaries on all aspects of women's healthcare including gynecology, obstetrics, and breast cancer. The manuscript management system is completely online and includes Visit http://www.dovepress.com/testimonials.php to read real quotes from published authors.

Submit your manuscript here: http://www.dovepress.com/international-journal-of-womens-health-journal 